\title{
Limited effect of anti-rheumatic treatment on 15-prostaglandin dehydrogenase in rheumatoid arthritis synovial tissue
}

Karina Roxana Gheorghe ${ }^{1}$, Syed Sadique ${ }^{1}$, Patrick Leclerc ${ }^{1}$, Helena Idborg ${ }^{1}$, Ivonne Wobst ${ }^{2}$, Anca Irinel Catrina ${ }^{1}$, Per-Johan Jakobsson ${ }^{1}$ and Marina Korotkova ${ }^{1,3^{*}}$

\begin{abstract}
Introduction: Rheumatoid arthritis (RA) is a chronic inflammatory disease in which prostaglandin $\mathrm{E}_{2}\left(\mathrm{PGE}_{2}\right)$ displays an important pathogenic role. The enzymes involved in its synthesis are highly expressed in the inflamed synovium, while little is known about 15- prostaglandin dehydrogenase (15-PGDH) that metabolizes $P G E_{2}$. Here we aimed to evaluate the localization of 15-PGDH in the synovial tissue of healthy individuals or patients with inflammatory arthritis and determine the influence of common RA therapy on its expression.

Methods: Synovial tissue specimens from healthy individuals, psoriatic arthritis, ostheoarthritis and RA patients were immunohistochemically stained to describe the expression pattern of 15-PGDH. In addition, the degree of enzyme staining was evaluated by computer analysis on stained synovial biopsies from two groups of RA patients, before and after RA specific treatment with either intra-articular glucocorticoids or oral methotrexate therapy. Prostaglandins derived from the cyclooxygenase (COX) pathway were determined by liquid-chromatography mass spectrometry in supernatants from interleukin (IL) $1 \beta$-activated fibroblast-like synoviocytes (FLS) treated with methotrexate.
\end{abstract}

Results: $15-\mathrm{PGDH}$ was present in healthy and inflamed synovial tissue, mainly in lining macrophages, fibroblasts and vessels. Intra-articular glucocorticoids showed a trend towards reduced 15-PGDH expression in RA synovium $(p=0.08)$ while methotrexate treatment left the $\mathrm{PGE}_{2}$ pathway unaltered both in biopsies ex vivo and in cultured FLS.

Conclusions: Early methotrexate therapy has little influence on the expression of $15-\mathrm{PGDH}$ and on any of the $P \mathrm{PE}_{2}$ synthesizing enzymes or COX-derived metabolites. Thus therapeutic strategies involving blocking induced $\mathrm{PGE}_{2}$ synthesis may find a rationale in additionally reducing local inflammatory mediators.

\section{Introduction}

Rheumatoid arthritis (RA) is a chronic autoimmune disease characterized by inflammation and extensive proliferation within the joint synovial tissue and by recruitment and activation of immune cells and subsequent cartilage and bone destruction. Rheumatoid joint displays an activated prostaglandin $\mathrm{E}_{2}\left(\mathrm{PGE}_{2}\right)$ pathway, and there are high levels of this mediator in the synovial fluid and strong expression in the synovium of its synthesizing

\footnotetext{
* Correspondence: marina.korotkova@ki.se

'Department of Medicine, Rheumatology Unit, Karolinska Institute/Karolinska University Hospital Solna, Stockholm, 17176 Sweden

Full list of author information is available at the end of the article
}

enzymes, microsomal prostaglandin $E_{2}$ synthase 1 (mPGES-1) as well as cyclooxygenase (COX) 1 and 2 [1]. Wheres COX-1 is considered a constitutive enzyme present under basal conditions, COX-2 is inflammationinduced [2] and co-localizes with MPGES-1 in the synovial tissue [3]. The deleterious role of $\mathrm{PGE}_{2}$ in the pathogenesis of RA has already been established and occurs through multiple mechanisms. $\mathrm{PGE}_{2}$ sustains inflammatory pathways by promoting expansion of auto-aggressive $\mathrm{T}$ helper 17 (Th17) cells [4], increases angiogenesis within the proliferating synovium, and regulates cartilage and bone metabolism by stimulation of osteoclast and matrix metalloproteinase activity. Pro-inflammatory cytokines, such as

\section{Biomed Central}


tumor necrosis factor (TNF) and interleukin-1-beta (IL$1 \beta)$, that orchestrate the pathological events in this disease are known inducers of mPGES- 1 and COX-2 expression [5].

The levels of $\mathrm{PGE}_{2}$ are determined not only by its synthesis but also by the rate of degradation. Most of the prostaglandin inactivation occurs through the action of 15-hydroxyprostaglandin dehydrogenase (15-PGDH), which converts $\mathrm{PGE}_{2}$ to a metabolite with greatly reduced biological activity [6] and is thus the main mechanism for $\mathrm{PGE}_{2}$ clearance. 15-PGDH is ubiquitously expressed in most mammalian tissues [6]. In humans, IL-6 [7] and transforming growth factor-beta (TGF $\beta$ ) regulate its expression in prostate and colon cancer, respectively, whereas TNF downmodulates it in colonocytes [8]. In addition, mediators controlling $\mathrm{PGE}_{2}$ formation reciprocally stimulate COX-2 while reducing 15-PGDH expression [9]. 15-PGDH decrease or loss was demonstrated in gastric [10], lung [11], and thyroid [12] tumors and results in increased malignant cell proliferation and cancer progression. In addition, reduced expression of 15-PGDH contributes to the elevated $\mathrm{PGE}_{2}$ levels observed in the systemic inflammatory response [13] or in the inflamed mucosa of patients with inflammatory bowel disease [8].

Recent reports demonstrated 15-PGDH synthesis in mouse articular chondrocytes and an inverse regulation of mPGES-1 and 15-PGDH by adipocyte-derived factors in these cells, resulting in boosted $\mathrm{PGE}_{2}$ levels [14]. Also, mechanical stress increases 15-PGDH mRNA expression in this system [15]. However, the presence and localization of this enzyme in human synovial tissue remain largely unknown.

Intra-articular glucocorticoids (GCs) are often used as efficient adjuvant therapy in RA to control for local inflammation. One of the mechanisms by which they achieve their anti-inflammatory effect relies also on inhibition of synovial mPGES-1 and COX-2 expression and formation of $\mathrm{PGE}_{2}$ [3]. Earlier reports evaluating the influence of dexamethasone on 15-PGDH demonstrated either induced expression in A549 cells [16] or inhibition of in vitro stimulated enzyme expression in a monocyte cell line [17].

In patients with RA, one of the most efficient drugs used in most cases as first-line therapy is methotrexate [18]. Its interference with the cellular folate metabolism results in immunosuppressive effects by inhibition of synovial inflammatory cell proliferation and enhancement of adenosine release. The influence of methotrexate on $\mathrm{PGE}_{2}$ production appears controversial; reports demonstrate inhibitory action in whole blood of patients with RA [19] and in fibroblast-like synoviocytes (FLSs) [20], but studies also point to no effect on $\mathrm{PGE}_{2}$ release by FLSs $[21,22]$.
We undertook this study to investigate the distribution of 15-PGDH in synovial tissue and the effects of methotrexate therapy on the synovial expression of the $\mathrm{PGE}_{2}$ pathway enzymes in patients with newly diagnosed RA and in vitro in cultured FLSs. Moreover, we analyzed the change in expression pattern for 15-PGDH induced by local administration of GCs known to have potent anti-inflammatory properties.

\section{Materials and methods}

\section{Patients and clinical data}

Synovial biopsies were collected at the time of surgical joint replacement from eight patients with RA and five with ostheoarthritis (OA). In addition, synovial samples from three healthy individuals and three patients with psoriatic arthritis (PsA) were obtained by arthroscopy. The biopsies were used for detection and cellular localization of synovial 15-PGDH.

To investigate the effects of anti-rheumatic treatment on the enzymes of the $\mathrm{PGE}_{2}$ cascade, synovial biopsies were collected from two cohorts of patients. In the first group, 13 patients with newly diagnosed RA were enrolled; the median time period since diagnosis was 7 days, and the median time since the beginning of symptoms was 6.5 months. Table 1 illustrates the clinical and laboratory data of the patient cohort. These patients had active disease with a Disease Activity Score in 28 joints (DAS28) of greater than 3.2 (mean of 5.7). All patients fulfilled the American College of Rheumatology criteria for RA [23]. At baseline and 1 year after inclusion in the

Table 1 Demographic, clinical, and laboratory data of the methotrexate study cohort

\begin{tabular}{lc}
\hline Characteristics of cohort & Value \\
\hline Number of patients & 13 \\
Median age (range), years & $56(32-78)$ \\
Number of males/females & $4 / 9$ \\
Median interval from diagnosis (range), days & $7(1-25)$ \\
Median duration of symptoms (range), months & $6.5(2-12)$ \\
ACPA-positive patients, number (percentage) & $6(46)$ \\
Rheumatoid factor-positive patients, number (percentage) & $9(69)$ \\
Number of patients taking oral corticosteroids & 2 \\
Number of patients taking NSAIDs & 10 \\
Median duration between biopsies (range), days & $58(45-70)$ \\
Number of patients presenting erosions (percentage) & $2(15)$ \\
$\quad$ At baseline & $7(53)$ \\
After 1 year & \\
Mean DAS28 (minimum, maximum) & $5.7(3.9,6.7)$ \\
At baseline & $3.8(1.8,5.8)$ \\
$\quad$ After 3 months
\end{tabular}

ACPA, anti-cyclic citrullinated peptide antibody; DAS28, Disease Activity Score in 28 joints; NSAID, non-steroidal anti-inflammatory drug. 
study, plane radiographs of the affected joint were evaluated for the presence of erosions. DAS28 was assessed at baseline and at a median of 3 months after treatment initiation. Patients were assigned to start methotrexate therapy with an initial dosage of $10 \mathrm{mg} /$ week, which was increased in a stepwise manner to achieve the final dosage of $20 \mathrm{mg} /$ week after 3 weeks. Synovial biopsies were obtained by arthroscopy from the same inflamed joint before methotrexate initiation and after a median of 8 weeks. Oral non-steroidal anti-inflammatory drugs (NSAIDs) and GCs in doses of up to $10 \mathrm{mg}$ daily were allowed, as was a maximum of three intra-articular GC injections in joints other than the one biopsied.

In the second group, 10 patients who had RA and active knee arthritis were recruited to the study. The clinical features of this patient group were published previously [24]. All patients in the second group received an intra-articular injection of $40 \mathrm{mg}$ of triamcinolone hexacetonide. Synovial biopsies were obtained prior to and a median of 10 days after treatment. All other anti-rheumatic medication was kept unchanged 2 weeks before the first arthroscopy and for the rest of the study period. All investigations were approved by the ethics committee of the Karolinska University Hospital, and participants gave written informed consent to participate in the study.

\section{Immunohistochemical evaluation}

Frozen serial biopsy sections were fixed in $2 \%$ formaldehyde, and immunohistochemical staining was performed by using rabbit polyclonal anti-serum raised toward mPGES-1 [1], rabbit polyclonal anti-15-PGDH (Novus Biologicals, Littleton, CO, USA) and anti-COX-1 (Cayman Chemical Company, Ann Harbor, MI, USA), and mouse monoclonal anti-COX-2 (CX229; Cayman Chemical Company) antibodies in accordance with a published protocol [25]. Stained sections were quantitatively evaluated by computer-based image analysis, and results were expressed as the percentage of positive stained area versus total tissue staining. For immunofluorescence experiments, sections were incubated with a mixture of primary antibodies against 15-PGDH and cell markers for macrophages (CD163, clone Ber-MAC3), fibroblasts (prolyl-4-hydroxylase, clone 5B5), B cells (CD20, clone L26) (all from DakoCytomation, Glostrup, Denmark), T cells (CD3, SK7; BD Biosciences, San Jose, CA, USA), and endothelial cells (CD31, clone EN4; Novakemi, Handen, Sweden) followed by the addition of secondary antibodies conjugated to Alexa 546 or Alexa 483 (Invitrogen Corporation, Carlsbad, CA, USA).

\section{In vitro culture of fibroblast-like synoviocytes and measurement of prostaglandins}

Commercially available FLSs (Dominion Pharmakine, S.L., Bizkaia, Spain) from patients with RA were grown in Dulbecco's modified Eagle's medium supplemented with $10 \%$ human serum and penicillin streptomycin (100 units $/ \mathrm{mL}$ ) in a humidified atmosphere containing $5 \% \mathrm{CO}_{2}$ at $37^{\circ} \mathrm{C}$. When reaching confluence, cells were passaged by gentle trypsinization and used between passages 4 and 6 . The cells were incubated for 48 hours with $10 \mathrm{ng} / \mathrm{mL}$ IL-1 $\beta$ (R\&D Systems, Abingdon, UK) in the presence or absence of 10 or $250 \mu \mathrm{M}$ methotrexate. Unstimulated cells were used as controls. After treatment, supernatants were collected and frozen at $-20^{\circ} \mathrm{C}$ until analyzed. Cells were trypsinised, washed twice in phosphate-buffered saline (PBS), and harvested for subsequent Western blot analysis.

Prostaglandin profiling of the primary prostaglandins $\left(\mathrm{PGE}_{2}, \mathrm{PGD}_{2}\right.$, and $\left.\mathrm{PGF}_{2 \alpha}\right)$ and of the metabolites of $\mathrm{PGI}_{2}$ and tromboxane $\mathrm{A}_{2}\left(\mathrm{TxA}_{2}\right)$ - 6-keto $\mathrm{PGF}_{1 \alpha}$ and $\mathrm{TxB}_{2}$, respectively - was accomplished by using liquid chromatography tandem mass spectrometry (LC-MS-MS). Cell culture supernatants were extracted with an Oasis HLB Extraction Plate (Waters Corporation, Milford, MA, USA) and analyzed by high-performance liquid chromatography by using Waters 2795 HPLC (Waters Corporation) coupled to a triple quadrupole mass spectrometer (Acquity TQ Detector; Waters Corporation). PGE $\mathrm{PE}_{2}$, $\mathrm{PGD}_{2}, \mathrm{PGF}_{2 \alpha}, \mathrm{TxB}_{2}, 6$-keto-PGF $1 \alpha$, and their corresponding deuterated standards were detected by using multiple reaction monitoring and quantified by using internal standard methodology and QuanLynx software (Waters Corporation).

\section{Western blot analysis of enzymes}

Cells were harvested after the different treatments and protein was extracted by using cell lysis buffer (Pierce, Rockford, IL, USA) in accordance with the instructions of the manufacturer. Total protein concentration was determined by using the NanoDrop technique, and equal amounts of protein were separated on $4 \%$ to $12 \%$ NuPage polyacrylamyde gels (Invitrogen Ltd., Paisley, UK). The resolved proteins were blotted onto polyvinylidene fluoride membranes (Pall Life Sciences, Pensacola, FL, USA), which were further blocked in PBS-Tween-20 buffer containing 5\% (wt/vol) non-fat dry milk for 1 hour at room temperature. Incubation with primary antibodies rabbit polyclonal anti-serum against mPGES-1, rabbit polyclonal anti-COX-2 (Cayman Chemical Company), rabbit polyclonal anti-15-PGDH (Cayman Chemical Company), or mouse monoclonal anti- $\beta$-actin (NeoMarkers, Freemont, CA, USA) was performed overnight at $4^{\circ} \mathrm{C}$. After washing in $0.05 \%$ TTBS (Tris-Tween-buffered saline), the membranes were incubated with horseradish peroxidaselinked anti-rabbit IgG from donkey (GE Healthcare, Stockholm, Sweden), washed extensively in $0.1 \%$ TTBS, and finally visualized by a chemiluminiscence detection kit (Thermo Scientific, Rockford, IL, USA) on film 
(Amersham Hybond; GE Healthcare, Buckinghamshire, $\mathrm{UK})$.

\section{Statistical analysis}

For statistical analysis of the methotrexate and GC cohorts, we used the Wilcoxon test for paired samples, followed by Bonferroni corrections for multiple comparisons, whereas in vitro data were analyzed by the MannWhitney test for unpaired samples. $P$ values of less than 0.05 were considered significant.

\section{Results}

\section{Distribution of 15-PGDH in rheumatoid arthritis synovial} tissue

All RA biopsy samples analyzed displayed 15-PGDH expression (Figure 1a). Its presence in RA synovial tissue was prominent in the synovial lining but also in scattered sublining macrophages and inflammatory infiltrates as well as vessels. Expression of 15-PGDH among patients was, nonetheless, variable; staining was strong and extensive in some patients and weak and confined mostly to the synovial membrane in others. In addition, the enzyme was present, albeit to a lesser extent, in healthy synovial tissue and in synovium from patients with OA and those with PsA (Figure 1b-d). Similarly to
RA, the enzyme was found mainly in the lining layer in healthy tissue, PsA, and OA, although the expression was somewhat weaker in the lining synovial cells of healthy individuals compared with RA.

Most 15-PGDH-expressing cells were identified by double-immunofluorescence as CD163-positive synovial macrophages and fibroblasts in RA synovium (Figure 2a left and middle panels). In addition, most sublining vessels stained positively for 15-PGDH in endothelial cells (Figure 2 right panel) whereas CD20-positive B cells and CD3-positive $T$ cells essentially lacked 15-PGDH enzyme (data not shown).

\section{Clinical evaluation and response to treatment}

Out of the 13 patients included in the methotrexate study cohort, seven were responders, defined as those who had good or moderate response to treatment according to the European League Against Rheumatism (EULAR) criteria, and six were non-responders. The overall mean DAS28 decreased significantly to 3.8 after 3 months of treatment. All patients receiving intraarticular GCs were clinical responders as assessed by the local clinical examination of the joint and macroscopic evaluation of the local inflammation during the second arthroscopy.
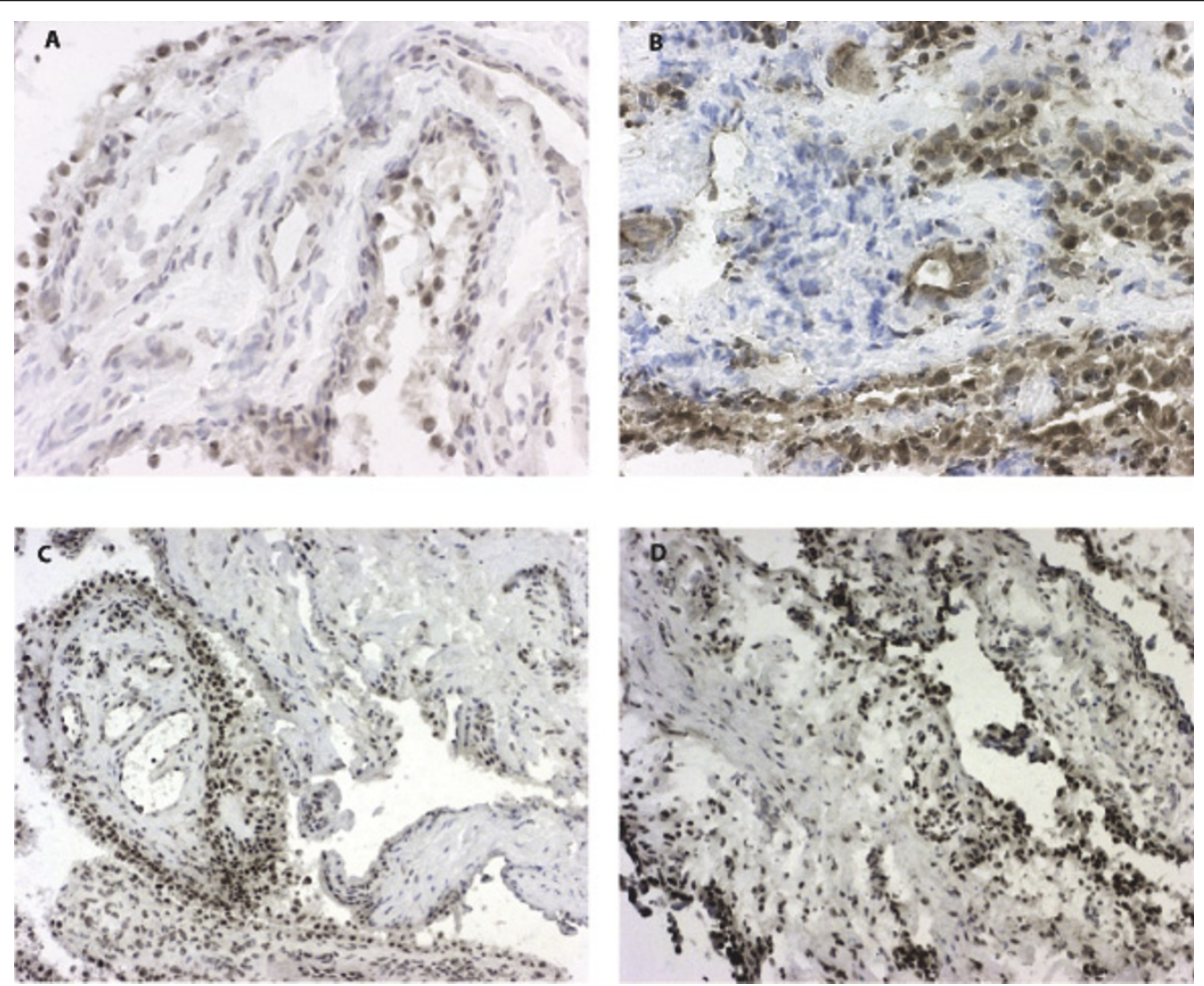

Figure 1 Expression of 15-prostaglandin dehydrogenase (15-PGDH) in healthy and inflamed synovial tissue. Immunohistochemical staining reveals positive (brown) staining for 15-PGDH (hematoxilin counterstained) in synovial tissue from healthy individuals (a) and patients with rheumatoid arthritis (b), osteoarthritis (c), or psoriatic arthritis (d). Original magnifications: $\times 250$ (a, b), $\times 100$ (c, d). 


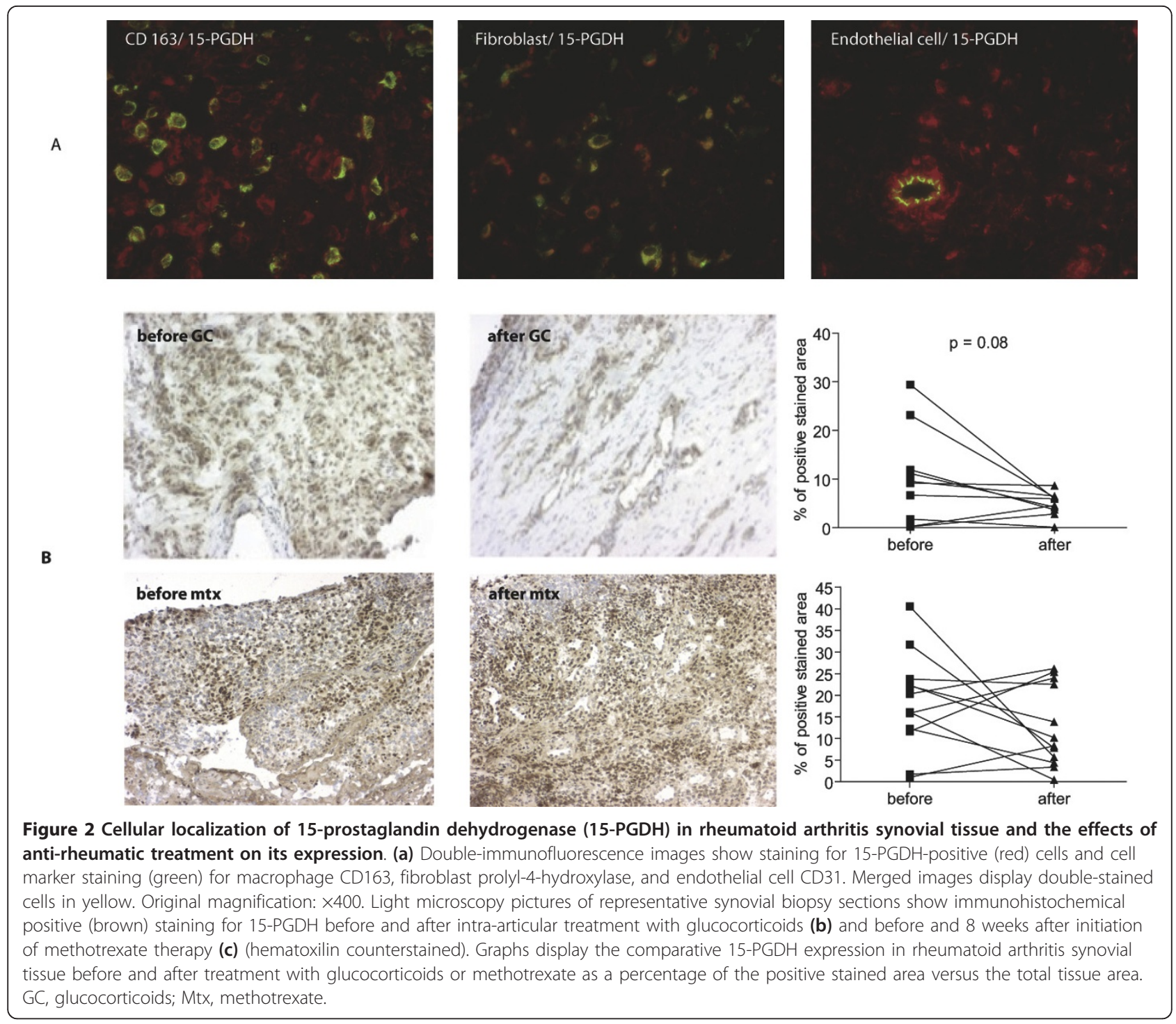

Effects of intra-articular steroid therapy on the expression of 15-PGDH in rheumatoid arthritis synovial tissue

We have earlier reported that intra-articular GC treatment downregulated the expression of $\mathrm{PGE}_{2}$-synthesizing enzymes in the rheumatoid synovium. Here, our results demonstrated that local GC therapy resulted in reduced expression of 15-PGDH in nine patients but that two patients showed increased values after therapy (Figure 2b). Overall, although no statistical difference $(P=0.08)$ was detected before or after local GC injection, there was a clear trend toward diminished enzyme expression following therapy.

Effects of methotrexate therapy on the expression of 15PGDH and related enzymes in rheumatoid arthritis joint We then studied the effect of oral methotrexate therapy on 15-PGDH and found that 8 weeks of oral methotrexate treatment did not significantly change the synovial expression level of 15-PGDH (Figure 2c). As the local $\mathrm{PGE}_{2}$ production is determined by its biosynthesis and degradation, we also examined whether methotrexate affects the biosynthetic enzymes. No effects of methotrexate on synovial expression of mPGES-1, COX-1, and COX-2 were detected (Figure 3). Stratifying patients according to response to treatment, presence of anti-cyclic citrullinated peptide antibodies, or erosion progression did not show any significant difference in enzyme expression between or within the groups (data not shown). We also found a similar overall staining pattern for $\mathrm{PGE}_{2}$-related enzymes irrespectively of NSAID treatment (data not shown).

In unstimulated in vitro cultured FLSs, low levels of $\mathrm{PGE}_{2}$ formation were mirrored by undetectable expression of COX-2 and mPGES-1 (Figure 4a, b). Still, FLSs displayed low 15-PGDH amounts even in basal conditions, 


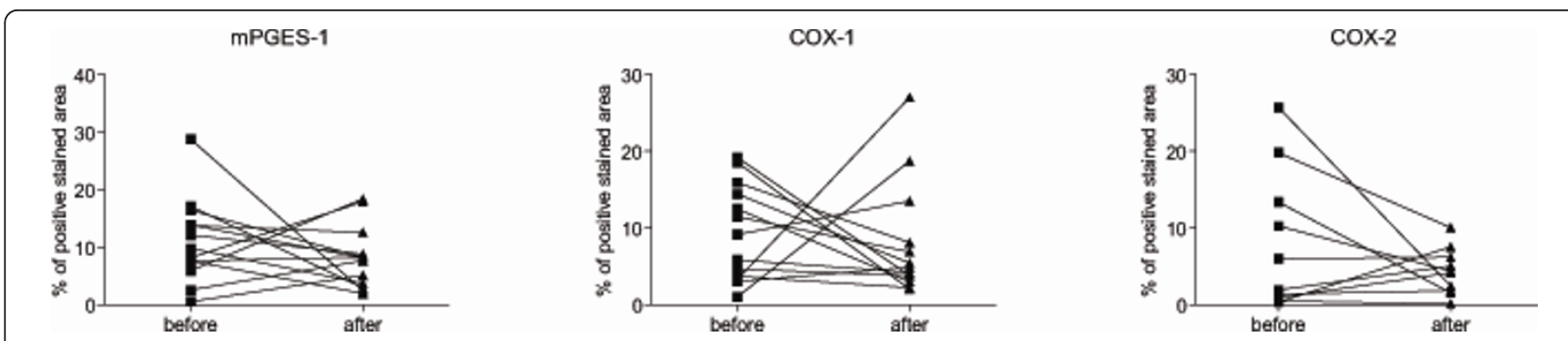

Figure 3 Effects of methotrexate on the expression of prostaglandin $E_{2}$ biosynthetic enzymes in rheumatoid synovium Immunohistochemical evaluation of positive staining for microsomal prostaglandin $E_{2}$ synthase 1 (mPGES-1), cyclooxygenase 1 (COX-1), and COX-2 in synovial tissue biopsies before and 8 weeks after initiation of methotrexate treatment. Results are expressed as a percentage of the positive stained area versus the total tissue area.

and this is in line with the presence of this enzyme in most tissues. As expected, IL-1 $\beta$ determined a strong increase in $\mathrm{PGE}_{2}$ production along with upregulation of enzyme expression. The increase in 15-PGDH expression following IL-1 $\beta$ stimulation was, however, modest in comparison with the dominant upregulation of the synthesizing enzymes mPGES-1 and COX-2, explaining the net effect of increased $\mathrm{PGE}_{2}$ synthesis. However, the addition of methotrexate in either low or high concentration did not abrogate the IL-1 $\beta$-induced effects on any studied enzyme expression or the $\mathrm{PGE}_{2}$ formation. Furthermore, analysis of the prostanoid profile by LC-MS-MS in supernatants

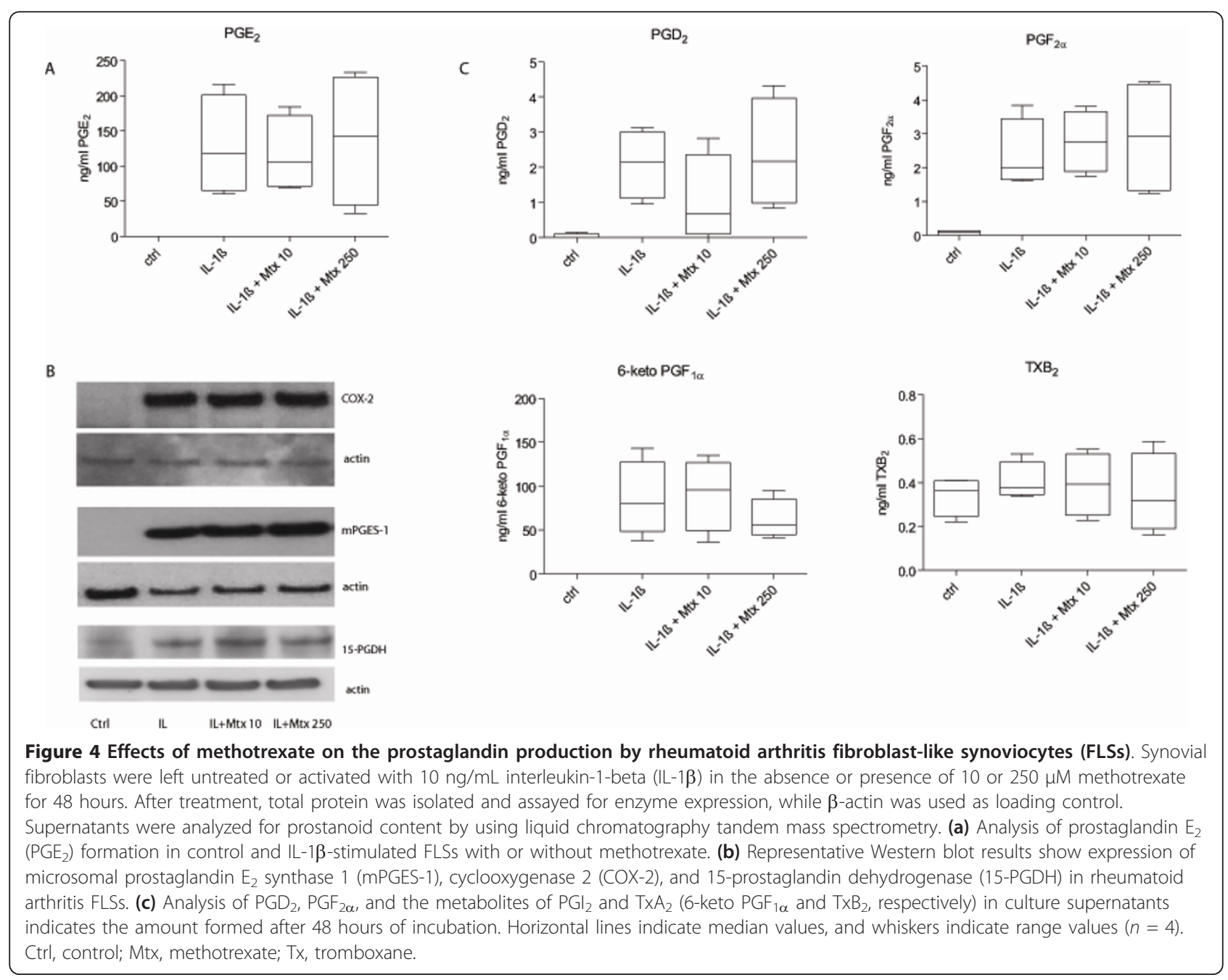


from stimulated and unstimulated FLSs showed that methotrexate had no influence on the formation of any of the lipid mediators derived from the COX pathway, as demonstrated by detection of $\mathrm{PGE}_{2}, \mathrm{PGD}_{2}$, and $\mathrm{PGF}_{2 \alpha}$ and metabolites of $\mathrm{PGI}_{2}$ or $\mathrm{TxA}_{2}$ (Figure 4c).

\section{Discussion}

The contribution of the $\mathrm{PGE}_{2}$ pathway to the RA pathogenic process has been well established, and most studies have focused on $\mathrm{PGE}_{2}$ and its inflammation-dependent synthesizing enzymes. However, 15-PGDH, the enzyme responsible for the degradation of $\mathrm{PGE}_{2}$, has received little attention in this context, although its level of expression ultimately determines the availability of $\mathrm{PGE}_{2}$.

We described here for the first time the distribution pattern of 15-PGDH in synovial tissue in both pathological (inflammatory) and healthy conditions. 15-PGDH was present in patients with RA and was localized mostly in the lining macrophages and sublining fibroblasts and vessels. This finding is in agreement with localization of the mPGES-1 and COX enzymes in RA synovial tissue [1], indicating the possibility for local regulation and balance of formation and removal of $\mathrm{PGE}_{2}$. An alternative view is that, in an effort to overcome the high prostaglandin burden in RA, 15-PGDH expression increases as a protective mechanism. Furthermore, the enzyme was present in OA and PsA synovium, and this is in line with the association of these conditions with variable degrees of inflammation in synovial tissue. To a lesser extent, we also identified 15-PGDH in the synovial lining of healthy individuals, indicating constitutive formation of $\mathrm{PGE}_{2}$ in synovial tissue. Expression of $\mathrm{PGE}_{2}$ pathway enzymes has been reported in non-inflammatory conditions in kidney [26] and muscle [27], suggesting a possible role for basal $\mathrm{PGE}_{2}$ production in local tissue homeostasis.

Intra-articular GCs relieve local symptoms in the inflamed RA joint and are successfully used as add-on therapy to control for occasional bouts of inflammation. In this study, we demonstrated that GC injections may decrease the expression of 15-PGDH in synovial tissue that in turn, may promote local accumulation of $\mathrm{PGE}_{2}$. However, previous data from our group showed reduced expression of mPGES-1 and COX after local GC treatment [3], resulting in a diminished $\mathrm{PGE}_{2}$ generation. Thus, the attenuated 15-PGDH expression observed here may reflect simply a negative feedback induced by low $\mathrm{PGE}_{2}$ availability. Also, although $\mathrm{PGE}_{2}$ has a pivotal role in bone remodeling and degradation [28], complete removal of $\mathrm{PGE}_{2}$ may not be beneficial as there is evidence for a protective role for basal $\mathrm{PGE}_{2}$ in the resolution phase of inflammation [29-31] as well as for suppression of B-cell proliferation by $\mathrm{PGE}_{2}$ [32]. Furthermore, it is important to keep in mind that 15-PGDH, though the key enzyme for catabolism of prostaglandins, is also involved in degradation of lipoxins [33], with essentially opposed activity in the inflammatory milieu. As such, the lack of effect or trend toward decreased 15-PGDH reported here by GC may, in fact, contribute to preserving anti-inflammatory lipid mediators.

Given the limitation of the analytical system used in our study, we cannot rule out that the change in positive staining may be the result of a decrease in the number of inflammatory cells expressing the enzymes rather than an actual reduction in cellular expression. Data from a previous study demonstrated that intra-articular corticosteroid therapy reduced the number of synovial $\mathrm{T}$ lymphocytes but that the number of macrophages remained unchanged [34]. Since mPGES-1, 15-PGDH, and the COX enzymes are detected mainly in the macrophage and fibroblast populations but are essentially lacking in synovial lymphocytes, it is reasonable to assume that the changes we detect may be due to both reduced cellular enzyme formation and reduced inflammatory cell infiltration.

Despite being the first line of therapy for RA [35] and highly efficient in many patients, oral methotrexate showed no significant influence on the enzymes coordinating $\mathrm{PGE}_{2}$ metabolism. Image analysis of mPGES-1 expression, though not detecting any statistically significant change, showed that only four out of 13 patients displayed an increased mPGES-1 staining but that in all others methotrexate decreased the positive stained area. Thus, we cannot exclude an actual effect of the given therapy toward decreased mPGES-1, had we had a larger study cohort. On the other hand, the lack of effect on the 15PGDH levels seen in our group of newly diagnosed subjects suggests local persistence of $\mathrm{PGE}_{2}$ in these patients. In fact, $\mathrm{PGE}_{2}$ availability despite methotrexate therapy could explain the progression in joint erosion seen in some of the responder patients. It is well known that methotrexate, through folate-dependent biosynthetic blockade, causes upstream accumulation of adenosine that turns on anti-inflammatory pathways by acting predominantly on A2A and A3 receptors [36]. In fact, experimental and clinical data suggest that the adenosine-mediated anti-inflammatory effect is the most prominent mechanism for low-dose methotrexate efficiency in RA. In this sense, inhibition of TNF [37] and IL-1 $\beta$ [38] actions and enhanced IL-10 [39] production were reported as indirect effects through adenosine release. Several reports suggest that methotrexate, administered either in vivo in animal models of arthritis [40] or added in vitro in different cell systems such as rat peritoneal macrophages [41] and human rheumatoid synoviocytes [20], may have inhibitory effects on $\mathrm{PGE}_{2}$ production. There is, however, evidence that methotrexate may fail to elicit a change in $\mathrm{PGE}_{2}$ in human fibroblasts $[22,42]$. Although study conditions and 
systems differ in the aforementioned studies, a clear and definite effect of methotrexate on the prostaglandin pathway in synovium-derived cells is not apparent. Our in vitro results demonstrated that, in RA FLSs, methotrexate had no influence on the $\mathrm{PGE}_{2}$ pathway or on any of the COX-derived lipid mediators. The increase in 15-PGDH expression following IL- $1 \beta$ treatment of synovial fibroblasts may be secondary to the high $\mathrm{PGE}_{2}$ amount formed under these circumstances, as $\mathrm{PGE}_{2}$ itself may induce 15PGDH mRNA expression [43].

An earlier study evaluating synovial biopsies after 4 months of methotrexate treatment indicated that the macrophages and lymphocyte populations are reduced in the RA synovium [44]. Recent data from the same cohort of patients as the one used in our study demonstrated that 8 weeks of oral methotrexate therapy reduced the number of synovial CD3-positive lymphocytes and, to a lesser extent, the CD68-positive macrophages (Shankar Revu, submitted manuscript). Although lining and sublining macrophages highly express the enzymes involved in $\mathrm{PGE}_{2}$ formation, we found no significant influence exerted by methotrexate in our study. However, our study was designed to detect early changes in the synovium after the start of therapy and thus additional effects may become evident later on.

\section{Conclusions}

$15-\mathrm{PGDH}$ is present in synovial tissue in conditions associated with inflammatory responses, such as OA, PsA, and RA, in a manner similar to that of the $\mathrm{PGE}_{2}$ synthesizing enzymes. Local GC treatment seems to reduce its expression, whereas oral methotrexate therapy exerts little influence in synovial tissue or in FLSs in vitro. Together, these results suggest that the inflammation-induced $\mathrm{PGE}_{2}$ pathway may not be properly targeted by anti-rheumatic treatment but instead persists and contributes to perpetuating inflammatory circuits in the rheumatoid synovium. As such, therapeutical attempts aiming at blocking the excessive production of $\mathrm{PGE}_{2}$ may be justified in order to offer additional benefit in reducing synovial inflammation and damage.

\footnotetext{
Abbreviations

15-PGDH: 15-prostaglandin dehydrogenase; COX: cyclooxygenase; DAS28: Disease Activity Score in 28 joints; FLS: fibroblast-like synoviocyte; GC: glucocorticoid; IL: interleukin; LC-MS-MS: liquid chromatography tandem mass spectrometry; $m P G E S-1$ : microsomal prostaglandin $E_{2}$ synthase 1; NSAID: non-steroidal anti-inflammatory drug; OA: ostheoarthritis; PBS: phosphate-buffered saline; PG: prostaglandin; PsA: psoriatic arthritis; RA: rheumatoid arthritis; TNF: tumor necrosis factor; TTBS: Tris-Tween-buffered saline; Tx: tromboxane.
}

\section{Acknowledgements}

This study was supported by grants from the Swedish Research Council, the Swedish Rheumatism Association, King Gustaf $\vee 80$ years Foundation, the Swedish Society of Medicine, the Karolinska Institutet Foundation, and VINNOVA.

\section{Author details}

${ }^{1}$ Department of Medicine, Rheumatology Unit, Karolinska Institute/Karolinska University Hospital Solna, Stockholm, 17176 Sweden. ${ }^{2}$ Institute for Clinical Pharmacology, Johann Wolfgang Goethe-University Frankfurt, Theodor Stern Kai 7, 60590 Frankfurt/Main, Germany. ${ }^{3}$ Actar AB, Nobels väg 3, Solna, 17165 Sweden.

\section{Authors' contributions}

KRG participated in the study design, carried out the immunohistochemistry staining and analysis, performed statistical data analysis, and drafted the manuscript. SS carried out the Western blot analysis. IW performed the initial immunohistochemistry studies. PL participated in Western blot data collection and interpretation. HI carried out the mass spectrometry studies. AIC contributed to study design and collection of patient data and samples. MK conceived the study, participated in its design and coordination, and contributed to manuscript drafting and revision. P-JJ contributed to study design, data interpretation, and manuscript revision. All authors read and approved the final manuscript.

\section{Competing interests}

MK is employed part-time by Actar AB. The other authors declare that they have no competing interests.

Received: 13 January 2012 Revised: 20 April 2012

Accepted: 22 May 2012 Published: 22 May 2012

\section{References}

1. Westman M, Korotkova M, af Klint E, Stark A, Audoly LP, Klareskog L, Ulfgren AK, Jakobsson PJ: Expression of microsomal prostaglandin $E$ synthase 1 in rheumatoid arthritis synovium. Arthritis Rheum 2004, 50:1774-1780.

2. Fitzpatrick FA: Cyclooxygenase enzymes: regulation and function. Curr Pharm Des 2004, 10:577-588.

3. Korotkova M, Westman M, Gheorghe KR, af Klint E, Trollmo C, Ulfgren AK, Klareskog L, Jakobsson PJ: Effects of antirheumatic treatments on the prostaglandin E2 biosynthetic pathway. Arthritis Rheum 2005, 52:3439-3447.

4. Chizzolini C, Chicheportiche R, Alvarez M, de Rham C, Roux-Lombard P, Ferrari-Lacraz S, Dayer JM: Prostaglandin E2 synergistically with interleukin-23 favors human Th17 expansion. Blood 2008, 112:3696-3703.

5. Thoren S, Jakobsson PJ: Coordinate up- and down-regulation of glutathione-dependent prostaglandin E synthase and cyclooxygenase-2 in A549 cells. Inhibition by NS-398 and leukotriene C4. Eur J Biochem 2000, 267:6428-6434.

6. Tai HH, Ensor CM, Tong M, Zhou H, Yan F: Prostaglandin catabolizing enzymes. Prostaglandins Other Lipid Mediat 2002, 68-69:483-493.

7. Tong M, Tai HH: Synergistic induction of the nicotinamide adenine dinucleotide-linked 15-hydroxyprostaglandin dehydrogenase by an androgen and interleukin- 6 or forskolin in human prostate cancer cells. Endocrinology 2004, 145:2141-2147.

8. Otani T, Iwasaki M, Inoue M, Sasazuki S, Tsugane S: Bowel movement, state of stool, and subsequent risk for colorectal cancer: the Japan public health center-based prospective study. Ann Epidemiol 2006, 16:888-894.

9. Tong M, Ding $Y$, Tai HH: Reciprocal regulation of cyclooxygenase-2 and 15-hydroxyprostaglandin dehydrogenase expression in A549 human lung adenocarcinoma cells. Carcinogenesis 2006, 27:2170-2179.

10. Backlund MG, Mann JR, Holla VR, Buchanan FG, Tai HH, Musiek ES, Milne GL, Katkuri S, DuBois RN: 15-Hydroxyprostaglandin dehydrogenase is downregulated in colorectal cancer. J Biol Chem 2005, 280:3217-3223.

11. Tai HH, Tong M, Ding Y: 15-hydroxyprostaglandin dehydrogenase (15PGDH) and lung cancer. Prostaglandins Other Lipid Mediat 2007, 83:203-208.

12. Quidville V, Segond N, Lausson S, Frenkian M, Cohen R, Jullienne A: 15Hydroxyprostaglandin-dehydrogenase is involved in anti-proliferative effect of non-steroidal anti-inflammatory drugs COX-1 inhibitors on a human medullary thyroid carcinoma cell line. Prostaglandins Other Lipid Mediat 2006, 81:14-30.

13. Ivanov Al, Romanovsky AA: Prostaglandin E2 as a mediator of fever: synthesis and catabolism. Front Biosci 2004, 9:1977-1993.

14. Gosset M, Berenbaum F, Salvat C, Sautet A, Pigenet A, Tahiri $K$, Jacques C: Crucial role of visfatin/pre-B cell colony-enhancing factor in matrix 
degradation and prostaglandin E2 synthesis in chondrocytes: possible influence on osteoarthritis. Arthritis Rheum 2008, 58:1399-1409.

15. Gosset M, Berenbaum F, Levy A, Pigenet A, Thirion S, Cavadias S, Jacques C: Mechanical stress and prostaglandin E2 synthesis in cartilage. Biorheology 2008, 45:301-320.

16. Tong M, Tai HH: 15-Hydroxyprostaglandin dehydrogenase can be induced by dexamethasone and other glucocorticoids at the therapeutic level in A549 human lung adenocarcinoma cells. Arch Biochem Biophys 2005, 435:50-55.

17. Tong M, Tai HH: Dexamethasone inhibits the induction of NAD (+)-dependent 15-hydroxyprostaglandin dehydrogenase by phorbol ester in human promonocytic U937 cells. Biochim Biophys Acta 2000, 1497:61-68.

18. Visser K, Verpoort KN, van Dongen $H$, van der Kooij SM, Allaart CF, Toes RE, Huizinga TW, van der Helm-van Mil AH: Pretreatment serum levels of anticyclic citrullinated peptide antibodies are associated with the response to methotrexate in recent-onset arthritis. Ann Rheum Dis 2008, 67:1194-1195.

19. Mello SB, Barros DM, Silva AS, Laurindo IM, Novaes GS: Methotrexate as a preferential cyclooxygenase 2 inhibitor in whole blood of patients with rheumatoid arthritis. Rheumatology (Oxford) 2000, 39:533-536.

20. Vergne P, Liagre B, Bertin P, Cook-Moreau J, Treves R, Beneytout JL, Rigaud M: Methotrexate and cyclooxygenase metabolism in cultured human rheumatoid synoviocytes. J Rheumatol 1998, 25:433-440.

21. Seitz M, Loetscher P, Dewald B, Towbin H, Baggiolini M: In vitro modulation of cytokine, cytokine inhibitor, and prostaglandin $\mathrm{E}$ release from blood mononuclear cells and synovial fibroblasts by antirheumatic drugs. J Rheumatol 1997, 24:1471-1476.

22. Meyer FA, Yaron I, Mashiah V, Yaron M: Methotrexate inhibits proliferation but not interleukin 1 stimulated secretory activities of cultured human synovial fibroblasts. J Rheumatol 1993, 20:238-242.

23. Arnett FC, Edworthy SM, Bloch DA, McShane DJ, Fries JF, Cooper NS, Healey LA, Kaplan SR, Liang MH, Luthra HS, Medsger TM Jr, Mitchell DM, Neustadt DH, Pinals RS, Schaller JG, Sharp JT, Wilder RL, Hunder GG: The American Rheumatism Association 1987 revised criteria for the classification of rheumatoid arthritis. Arthritis Rheum 1988, 31:315-324.

24. Gheorghe KR, Korotkova M, Catrina Al, Backman L, af Klint E, Claesson HE, Radmark O, Jakobsson PJ: Expression of 5-lipoxygenase and 15lipoxygenase in rheumatoid arthritis synovium and effects of intraarticular glucocorticoids. Arthritis Res Ther 2009, 11:R83.

25. Ulfgren AK, Lindblad S, Klareskog L, Andersson J, Andersson U: Detection of cytokine producing cells in the synovial membrane from patients with rheumatoid arthritis. Ann Rheum Dis 1995, 54:654-661.

26. Schneider A, Zhang Y, Zhang M, Lu WJ, Rao R, Fan X, Redha R, Davis L, Breyer RM, Harris R, Guan Y, Breyer MD: Membrane-associated PGE synthase-1 (mPGES-1) is coexpressed with both COX-1 and COX-2 in the kidney. Kidney Int 2004, 65:1205-1213.

27. Korotkova M, Helmers SB, Loell I, Alexanderson H, Grundtman C, Dorph C, Lundberg IE, Jakobsson PJ: Effects of immunosuppressive treatment on microsomal prostaglandin E synthase 1 and cyclooxygenases expression in muscle tissue of patients with polymyositis or dermatomyositis. Ann Rheum Dis 2008, 67:1596-1602.

28. Blackwell KA, Raisz LG, Pilbeam CC: Prostaglandins in bone: bad cop, good cop? Trends Endocrinol Metab 21:294-301.

29. Chan MM, Moore AR: Resolution of inflammation in murine autoimmune arthritis is disrupted by cyclooxygenase- 2 inhibition and restored by prostaglandin E2-mediated lipoxin A4 production. J Immunol 184:6418-6426.

30. Su WH, Cheng MH, Lee WL, Tsou TS, Chang WH, Chen CS, Wang PH: Nonsteroidal anti-inflammatory drugs for wounds: pain relief or excessive scar formation? Mediators Inflamm 2010, 2010:413238.

31. Degousee N, Fazel S, Angoulvant D, Stefanski E, Pawelzik SC, Korotkova M, Arab S, Liu P, Lindsay TF, Zhuo S, Butany J, Li RK, Audoly L, Schmidt R, Angioni C, Geisslinger G, Jakobsson PJ, Rubin BB: Microsomal prostaglandin E2 synthase-1 deletion leads to adverse left ventricular remodeling after myocardial infarction. Circulation 2008, 117:1701-1710.

32. Murn J, Alibert $\mathrm{O}, \mathrm{Wu} N$, Tendil $\mathrm{S}$, Gidrol $\mathrm{X}$ : Prostaglandin E2 regulates $B$ cell proliferation through a candidate tumor suppressor, Ptger4. J Exp Med 2008, 205:3091-3103.

33. Clish CB, Levy BD, Chiang N, Tai HH, Serhan CN: Oxidoreductases in lipoxin A4 metabolic inactivation: a novel role for 15 -onoprostaglandin 13-reductase/leukotriene B4 12-hydroxydehydrogenase in inflammation. J Biol Chem 2000, 275:25372-25380.

34. af Klint E, Grundtman C, Engstrom M, Catrina Al, Makrygiannakis D, Klareskog L, Andersson U, Ulfgren AK: Intraarticular glucocorticoid treatment reduces inflammation in synovial cell infiltrations more efficiently than in synovial blood vessels. Arthritis Rheum 2005, 52:3880-3889.

35. Visser K, Katchamart W, Loza E, Martinez-Lopez JA, Salliot C, Trudeau J, Bombardier C, Carmona L, van der Heijde D, Bijlsma JW, Boumpas DT, Canhao H, Edwards CJ, Hamuryudan V, Kvien TK, Leeb BF, Martín-Mola EM, Mielants H, Müller-Ladner U, Murphy G, Østergaard M, Pereira IA, RamosRemus C, Valentini G, Zochling J, Dougados M: Multinational evidencebased recommendations for the use of methotrexate in rheumatic disorders with a focus on rheumatoid arthritis: integrating systematic literature research and expert opinion of a broad international panel of rheumatologists in the 3E Initiative. Ann Rheum Dis 2009, 68:1086-1093.

36. Tian $\mathrm{H}$, Cronstein BN: Understanding the mechanisms of action of methotrexate: implications for the treatment of rheumatoid arthritis. Bull NYU Hosp Jt Dis 2007, 65:168-173.

37. Sajjadi FG, Takabayashi K, Foster AC, Domingo RC, Firestein GS: Inhibition of TNF-alpha expression by adenosine: role of $A 3$ adenosine receptors. J Immunol 1996, 156:3435-3442.

38. Seitz M, Loetscher P, Dewald B, Towbin H, Rordorf C, Gallati H, Baggiolini M, Gerber NJ: Methotrexate action in rheumatoid arthritis: stimulation of cytokine inhibitor and inhibition of chemokine production by peripheral blood mononuclear cells. Br J Rheumatol 1995, 34:602-609.

39. Hasko G, Szabo C, Nemeth ZH, Kvetan V, Pastores SM, Vizi ES: Adenosine receptor agonists differentially regulate IL-10, TNF-alpha, and nitric oxide production in RAW 264.7 macrophages and in endotoxemic mice. J Immunol 1996, 157:4634-4640.

40. Novaes GS, Mello SB, Laurindo IM, Cossermelli W: Low dose methotrexate decreases intraarticular prostaglandin and interleukin 1 levels in antigen induced arthritis in rabbits. J Rheumatol 1996, 23:2092-2097.

41. Williams A, Goodfellow R, Topley N, Amos N, Williams B: The suppression of rat collagen-induced arthritis and inhibition of macrophage derived mediator release by liposomal methotrexate formulations. Inflamm Res 2000, 49:155-161.

42. Inoue H, Takamori M, Nagata N, Nishikawa T, Oda H, Yamamoto S, Koshihara Y: An investigation of cell proliferation and soluble mediators induced by interleukin 1 beta in human synovial fibroblasts: comparative response in osteoarthritis and rheumatoid arthritis. Inflamm Res 2001, 50:65-72.

43. Frenkian M, Pidoux E, Baudoin C, Segond N, Jullienne A: Indomethacin increases 15-PGDH mRNA expression in HL60 cells differentiated by PMA. Prostaglandins Leukot Essent Fatty Acids 2001, 64:87-93.

44. Dolhain RJ, Tak PP, Dijkmans BA, De Kuiper P, Breedveld FC, Miltenburg AM: Methotrexate reduces inflammatory cell numbers, expression of monokines and of adhesion molecules in synovial tissue of patients with rheumatoid arthritis. Br J Rheumatol 1998, 37:502-508.

doi:10.1186/ar3851

Cite this article as: Gheorghe et al: Limited effect of anti-rheumatic treatment on 15-prostaglandin dehydrogenase in rheumatoid arthritis synovial tissue. Arthritis Research \& Therapy 2012 14:R121.

\section{Submit your next manuscript to BioMed Central and take full advantage of:}

- Convenient online submission

- Thorough peer review

- No space constraints or color figure charges

- Immediate publication on acceptance

- Inclusion in PubMed, CAS, Scopus and Google Scholar

- Research which is freely available for redistribution

Submit your manuscript at www biomedcentral.com/submit
C Biomed Central 